\title{
Analysis of Soil Erosion Causative Factors and Susceptibility in Anambra State, Southeastern, Nigeria
}

\author{
Romanus Udegbunam Ayadiuno and Dominic Chukwuka Ndulue \\ Department of Geography, University of Nigeria, Nsukka Enugu, Nigeria \\ Corresponding author email: chukwuka.ndulue.195839@unn.edu.ng
}

\section{ABSTRACT}

Soil erodibility depends on the texture, aggregate stability, shear strength, infiltration capacity, organic and chemical contents of the soil. This study considers other factors of soil erosion both static and dynamic which include slope, land use/land cover, soil erodibility and dynamic factors such as land surface temperature (LST), Soil Moisture Index (SMI) and rainfall erosivity are the variables for this research. The study area is Anambra State Southeastern Nigeria. This research used both primary and secondary data. Secondary data include Satellite images, aerial photo, topographic maps, meteorological and population data collected from different governmental and non-governmental organizations. The primary data involved field survey and observations using Global Positioning System (GPS) for ground truth verification and collection of soil samples for extraction of soil properties. Eight (8) prominent Causative Factors (CFs), factors were identified, which include drainage density, Lineament Density, Slope Length and Soil Erodibility as static factors, and Land Surface Temperature, Soil Moisture Index, Normalized Difference Vegetation Index and Rainfall Erosivity as dynamic factors. These Causative Factors (CFs), were analyzed and tested with Hierarchical Regression Model using SPSS version 20 software. Conclusively, the research showed that the dynamic causative factors influences soil susceptibility and triggers erosion hazards in Anambra State, Southeastern Nigeria. The approach employed is very important to sustainable land-use management and erosion prevention. Therefore, appropriate selections of the vital causative factors are required in order to achieve accurate estimate and sustainable mediation.

\section{KEY WORDS: SOIL ERODIBILITY, CAUSATIVE FACTORS, ANAMBRA STATE, EROSION, SUSCEPTIBILITY.}

\section{INTRODUCTION}

Background of the Study: Soil susceptibility is proneness of soil to be eroded by running water. Erodibility on the other hand is a measure of a soil's susceptibility to particle detachment and transport by agents of erosion. Therefore, soil erosion is termed erodibility. Erodibility is strictly attributed to soils while erosivity is a rainfall attribute. The two terms are used interchangeably and one cannot discuss susceptibility of soils without talking about erodibility. Soil erodibility is usually regarded as the susceptibility of a soil to erode. In a fundamental sense, it should be defined as the amount of soil loss per unit exogenic force or erosivity such as rainfall, surface flow

Biosc Biotech Res Comm P-ISSN: 0974-6455 E-ISSN: 2321-4007

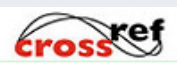

Identifiers and Pagination

Year: 2021 Vol: 14 No (9) Special Issue

Pages: 212-218

This is an open access article under Creative

Commons License Attribn 4.0 Intl (CC-BY).

DOI: $h t t p: / / d x$.doi.org/10.21786/bbrc/14.9.40 and seepage. Knowledge of soil erodibility has been useful in soil loss predictions (Wischmeier, 1960; Ayadiuno, Ndulue, Mozie \&t Ndichie, 2021).

Soil erosion process involves interaction of different complex biophysical and anthropogenic factors including soil properties, topography, climatic condition, land use, population and management practices. These factors vary both spatially and temporally from one location to the other (Shi et al., 2013), (Shakirudeen et al., 2018) had it that soil erosion creates serious implication on water quality and downstream siltation with great consequences on biodiversity and ecosystem services including domestic and industrial usage. The study of soil susceptibility to erosion will consider the factors of soil erosion both static and dynamic factors including slope, land use/land cover, soil erodibility and dynamic factors such as land surface temperature (LST), Stream Moisture Index (SMI) and rainfall erosivity all of which are the variables for this research.

Soil erodibility is a function of soil texture, infiltration capacity, shear strength, aggregate stability, organic matter, vegetation and chemical contents of the soil

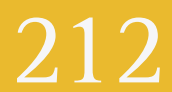


(Nwunonwo, 2013); (Ndukwe et al., 2013) (JafarZadeh, et al.,2014); (Ayadiuno \&t Ndulue 2021). Unsustainable land use practices leads to an addition of environmental challenges of soil erosion which is caused by anthropogenic activities especially in developing countries (Shakirudeen, et. al, 2018) (Igwe \& Egbueri, 2018) (Emeh \&t Igwe, 2018). Land use and land management practices have serious impacts on natural resources including water, soil nutrients; other effects on land include urban sprawl, land degradation, salinization and desertification (Igbokw \& Ejikeme, 2013). Research findings by (Igwe \&t Egbueri 2018) revealed that poor geotechnical properties and anthropogenic activities predispose these soils to be susceptible to erosion.

The rate of operation of erosion hazards in Anambra is high and variations in their intensity could be due to differences in Causative factors and type of geologic formation (Egbueri \& Igwe, 2020). Anambra State has more of the youngest and friable sedimentary deposit hence the highest number of erosion sites (over 700) (Ifejiofor, 2019), (Orji Et Nwankwoala, 2019), while Ebonyi State with the least or fewest number of erosion sites (over 250) (Orji \&t Nwankwoala, 2019) has more of the oldest and well consolidated sediments (Nwajide 2013), hence the need for a research such as this in Anambra state.

\section{MATERIAL AND METHODS}

Study Area: Anambra state lies between latitudes and longitudes 6000' and 7000" North, and 6045' and $7020^{\prime}$ East with a land mass of about $4844 \mathrm{~km} 2$ (figure 1). It is located within the humid tropical rainforest zone of West Africa. There is increased human activity in the area of urbanization, development of infrastructure such as road construction, expansion of existing ones and other primary extractive activities like deforestation and quarrying that have exposed the bare and led to the loss of the original ecosystem and biodiversity (Igwe \& Egbueri 2018) (Ayadiuno \&t Ndulue, 2021).

There are two distinct seasons in study area and they are the rainy season which starts from April and ends in October and the dry season which starts from November and ends in March respectively. The effect of Climate change has exacerbated more, the problems and menace of soil erosion in addition to already anthropogenic inflicted problems on land use in the study area (Farauta, et. al., 2012) (Igwe \&t Egbueri 2018) (Ayadiuno \&t Ndulue, 2021).

This research used both primary and secondary data. The primary data are measurements taken from frequent geo-physical field visit, surveys and observations. Global Positioning System (GPS) was used for ground truth verification. Secondary data consulted and used are Satellite images, aerial photo, topographic maps, meteorological and population data collected from different governmental and non-governmental organizations, and other published and non published literatures. The identified causative factors - Drainage
Density (DD), Erosion Density (ED), Lineament Density (LD), Slope Length (LS), Land Surface Temperature (LST), Normalized Difference Vegetation Index (NDVI), Rainfall and Soil Moisture Index (SMI), were subjected to statistical analysis (Hierarchical Regression) using the statistical package for the social sciences (SPSS) soft ware version 20 to determine and predict the contribution of the various identified causative factors that can induce, initiate and or trigger soil erosion in the study area. The equation is stated thus:

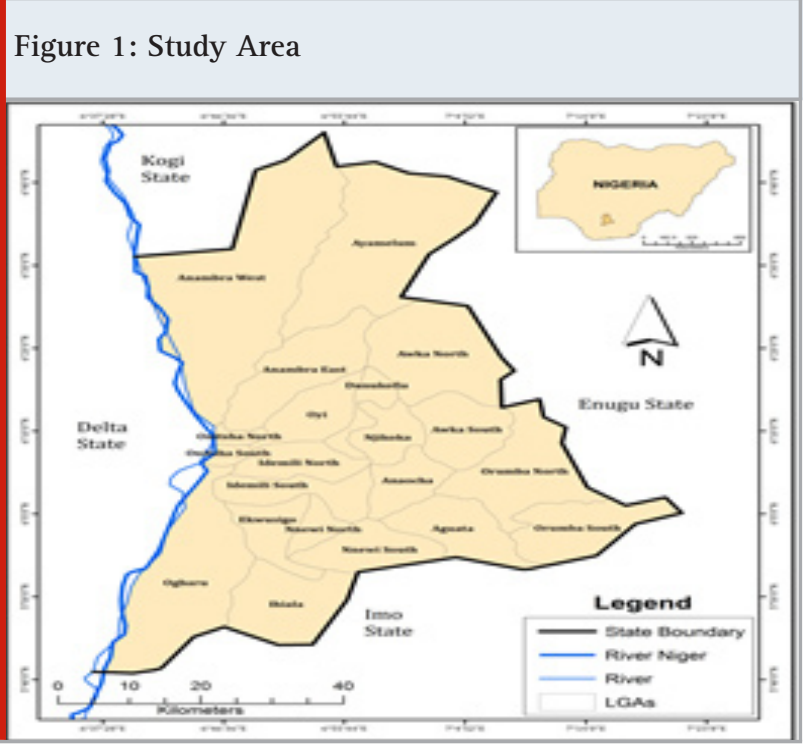

Source: USGS, Modified by the Authors, (2021) (GPS) was used for ground truth verification. Secondary data consulted and used are Satellite images, aerial photo, topographic maps, meteorological and population data collected from different governmental and nongovernmental organizations, and other published and non published literatures. The identified causative factors - Drainage Density (DD), Erosion Density (ED), Lineament Density (LD), Slope Length (LS), Land Surface Temperature (LST), Normalized Difference Vegetation Index (NDVI), Rainfall and Soil Moisture Index (SMI), were subjected to statistical analysis (Hierarchical Regression) using the statistical package for the social sciences (SPSS) soft ware version 20 to determine and predict the contribution of the various identified causative factors that can induce, initiate and or trigger soil erosion in the study area. The equation is stated thus:

$$
Y_{1}=\beta_{0}+\beta_{1} \alpha_{1}+\epsilon_{1}
$$

where

$$
\begin{aligned}
& \mathrm{Y}_{1}=\text { Dependent variable } \\
& \boldsymbol{\beta}_{\mathrm{o}}=\text { Intercept } \\
& \boldsymbol{\beta}_{1}=\text { Beta coefficient } \\
& \mathrm{x}_{1}=\text { Independent variable } \\
& \boldsymbol{\epsilon}_{1}=\text { Random Error term }
\end{aligned}
$$

Analysis of variation (ANOVA) was also carried out and F-ratio was evaluated to assess the improvement of the 
model by addition of the dynamic CFs. F-ratio represents the ratio of improvement in the model prediction to the residual errors present in the model. ANOVA is given by the formula.

$$
\begin{aligned}
& \mathrm{SS}=\sum \frac{(\mathrm{x}-\overline{\mathrm{x}})^{2}}{\mathrm{~N}-1} \\
& \mathrm{MS}=\sum \frac{(\mathrm{x}-\overline{\mathrm{x}})^{2}}{\mathrm{df}}
\end{aligned}
$$

Where

$$
\begin{aligned}
& x=\text { Variables } \\
& \bar{x}=\text { Mean } \\
& \mathrm{N}=\text { Number of observation } \\
& \mathrm{df}=\text { Degree of freedom }
\end{aligned}
$$

\section{RESULTS AND DISCUSSION}

Determination of the Influence of the Studied Variables on the K-Factor: A hierarchical regression model was applied to evaluate the influence of the variables in the model. All the assumptions of multiple regression which guides Hierarchical regression were examined - Normality test (Shapiro-wilk test), Independence, multicollinearity test (residual analysis) and outliers check using Z-Score statistic. HR was carried out on all the variables and 'not significant model' was obtained. An exploratory data analysis was then done and the variables were divided into blocks and grouped based on the k-factor. Each of the blocks was then analyzed and the results are shown below.
Six (6) blocks were considered and grouped together starting from Block 1 with just one variable LST. This block explains only 39\% of the variation in the k-factor as determined by the adjusted $\mathrm{R}^{2}$ in Table 28. In Block 2, LD was combined with $\mathrm{R}$, which led to an increase in the value of $\mathrm{R}^{2}$ to $70.7 \%$. In Block 3, DD, LD and NDVI were considered and they increased the value of adjusted $\mathrm{R}^{2}$ to $82.6 \%$. In Block 4, when four variables ED, LD, NDVI and $\mathrm{R}$ were considered, the block explained $89.5 \%$. The variables in block 5 are DD, ED, LD, LST and R which explained 98.0\%. When more variables DD, ED, LD, LS, LST and $\mathrm{R}$ were considered in blocks 6 , there was an increase in adjusted $\mathrm{R}^{2}$ to $97.6 \%$.

The model summary in the table above shows the variability in soil loss occurrence that can be accounted for by the individual as well as all the CFs in the model blocks. This was evaluated by analyzing the changes in the coefficient of the determination $\left(\mathrm{R}^{2}\right)$ values for each Block in the model. The coefficient of the determination $\left(\mathrm{R}^{2}\right)$, explains the percentage prediction made by the independent variables to the dependent variable. The independent variables predicted 46.7\% (NDVI) in Block 1; 78\% (LD and R) in Block 2; 89.1\% (DD, LD and NDVI) in Block 3; 94.8\% (DD, ED, LD, LST and R) in Block 4; 99.3\% (DD, ED, LD, LST and R) in Block 5 and 99.4\% (DD, ED, LD, LS, LST and R) in Block 6 respectively as causative factors of soil erosion (k-factor). In other

\begin{tabular}{|c|c|c|c|c|c|}
\hline Block & Variables & $\mathbf{R}^{2}$ & Adjusted $\mathbf{R}^{2}$ & $\mathbf{R}^{2}$ (pred) & Durbin-Watson \\
\hline 1 & NDVI & 46.7 & 39 & 0.00 & 1.17908 \\
\hline 2 & $\mathrm{LD}, \mathrm{R}$ & 78.0 & 70.7 & 0.00 & 1.22525 \\
\hline 3 & $\mathrm{DD}, \mathrm{LD}, \mathrm{NDVI}$ & 89.1 & 82.6 & 21.07 & 1.11047 \\
\hline 4 & ED, LD, NDVI, R & 94.8 & 89.5 & 33.79 & 1.36101 \\
\hline 5 & DD, ED, LD, LST, R & 99.3 & 98.0 & 69.15 & 2.93702 \\
\hline 6 & $\mathrm{DD}, \mathrm{ED}, \mathrm{LD}, \mathrm{LS}, \mathrm{LST}, \mathrm{R}$ & 99.4 & 97.6 & 46.39 & 3.13247 \\
\hline
\end{tabular}
words - DD, ED, LD, LS, LST and R contributed 99.4\% to soil erosion hazards in the study area. This implies that the combination contributed the highest out of all the causative factors examined in this study, leaving the rest with only $0.6 \%$
The Model of Summary table also shows that the DurbinWatson levels ranged from 1.11047 in block 3 to 3.13247 in block 6 . The levels are within $0-4$, even though the levels tended towards 1.1 - 3.1 which indicates that blocks 1, 2, 3 and 4 have very weak negative correlation, while blocks 5 and 6 have very weak positive correlation, but are all significant since there is no general rule to what is acceptable or not, outside the critical value. However, between 1.5 and 2.5 generally would have been better. The implication is that the model is significant.
Table 2 above shows the Analysis of Variance table for the group which contain the F-value and p-values for testing of the significance of each model in each block. Block 1 is significant with an F-value of 6.12 and P-value of 0.043 , since the P-value is less than 0.05. In Blocks 2, F-value is 10.65 and $\mathrm{P}$-value is 0.011 , and is significant since the P-value is less than 0.05. In Block 3, F-value is 13.63 and $\mathrm{P}$-value is 0.008 , and is not significant since the P-value is greater than 0.05; likewise in block 4, F-value is 18.06 and $\mathrm{P}$-value is 0.008 , and is significant since the $\mathrm{P}$-value is greater than 0.05. In Block 5, F-value 
is 79.50 and $\mathrm{P}$-value is 0.002 , and is significant since the P-value is less than 0.05, and in Block 6, F-value is 55.32 and $\mathrm{P}$-value is 0.018 , and is also significant since the P-value is less than 0.05 . The results show that all the blocks are significant and therefore considered as the best group depending on the variables of interest.

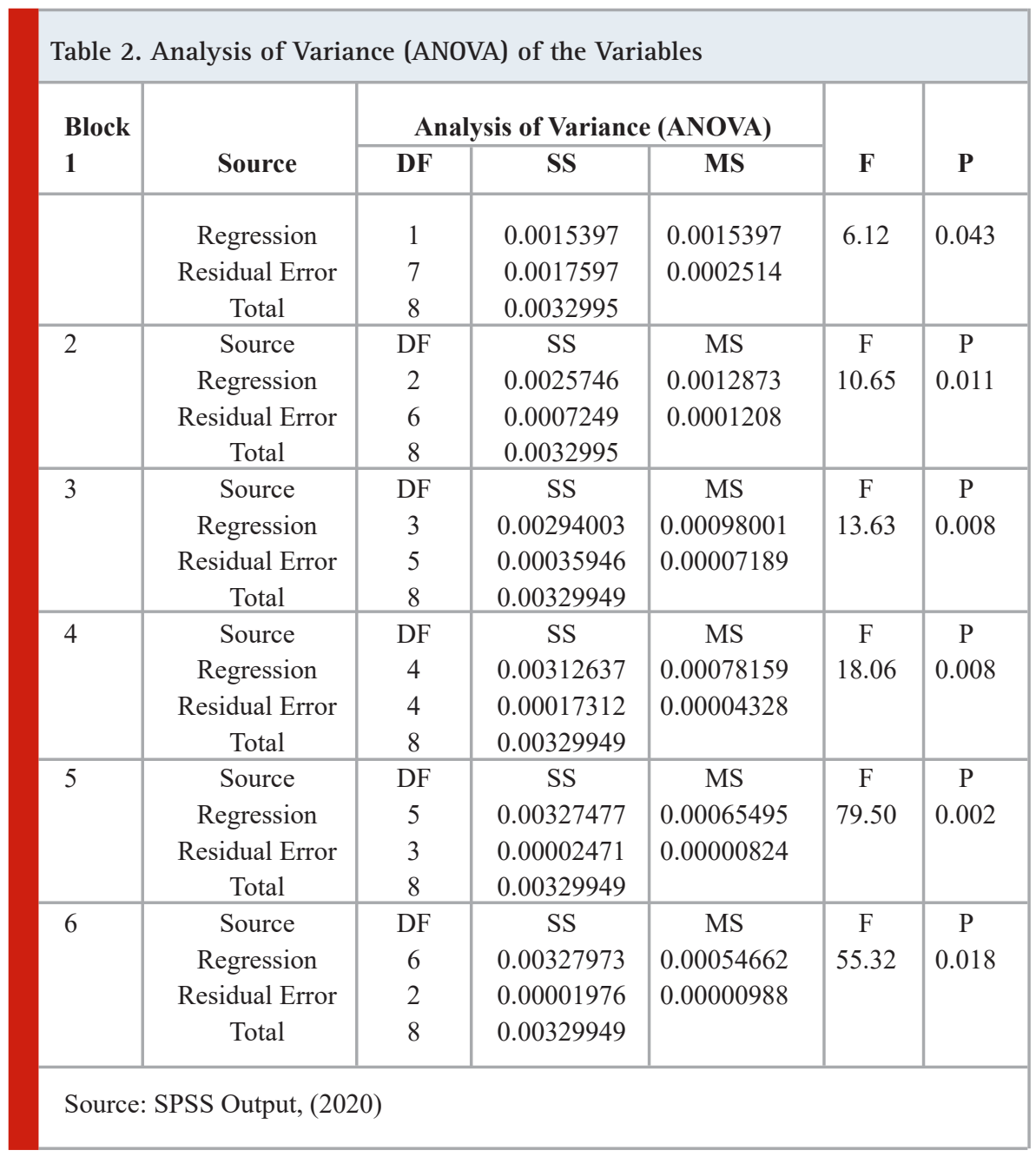

Table 3 above shows the coefficient(s) estimate as well as the p-values for testing of the significance level at 0.05 for each block. The coefficient(s) table above shows the individual contribution of the predictor(s) variables to the response or dependent variable and is used to explain the multiple linear regression equation which is thus:

$$
\mathrm{Y}_{1}=\beta_{\mathrm{o}}+\beta_{1} \alpha_{1}+\epsilon_{1}
$$

In Block $1, Y_{1}=0.06541+0.4628(N D V I)$. This means that the value 0.06541 is the base constant; that is, the value of $\mathrm{K}$ - factor before the effect of changes in the predictor variable is noticed. The equation means that every unit increase in NDVI, will increase K - factor by 0.4628 .

In Block $2, \mathrm{Y}_{1}=-1.0364+0.07789(\mathrm{LD})+0.00013733(\mathrm{R})$. This means that the value -1.0364 is the base constant; that is, the value of $\mathrm{K}$ - factor before the effect of change in the predictor variables is noticed. The equation means that every unit increase in LD will increase $\mathrm{K}$ - factor by 0.07789 , while every unit increase in $\mathrm{R}$ will increase $\mathrm{K}$ - factor by 0.00013733.
In Block 3, $Y_{1}=0.00753+0.5974(E D)+0.12172(\mathrm{LD})+$ 0.5032 (NDVI). This means that the value 0.00753 is the base constant; that is, the value of $\mathrm{K}$ - factor before the effect of change in the predictor variables is noticed. The equation means that every unit increase in ED will increase K - factor by 0.5974 , while every unit increase in LD and NDVI will increase K - also by 0.12172 and 0.5032 respectively.

In Block $4, \mathrm{Y}_{1}=-0.4672+0.4233(\mathrm{ED})+0.11499(\mathrm{LD})$ $+0.3477(\mathrm{NDVI})+0.00005993(\mathrm{R})$. This means that the value -0.4672 is the base constant; that is, the value of $\mathrm{K}$ - factor before the effect of change in the predictor variables is noticed. The equation means that every unit increase in ED, LD, NDVI and R will increase K - factor by $0.4233,0.11499$, and 0.00001569 , while every unit increase in ED and LD will increase K - factor by 0.3157 0.3477 and 0.00005993 respectively.

In Block 5, $\mathrm{Y}_{1}=-0.3397+0.11055(\mathrm{DD})+0.6357(\mathrm{ED})+$ $0.102061(\mathrm{LD})-0.0065177(\mathrm{LST})+0.00007163(\mathrm{R})$. This means that the value -0.3397 is the base constant; that 
is, the value of $\mathrm{K}$ - factor before the effect of change in the predictor variables is noticed. The equation means that every unit increase in DD, ED, LD and R will increase $\mathrm{K}$ - factor by $0.11055,0.6357,0.102061$ and 0.00007163 respectively, while every unit increase in LST will decrease K - factor by 0.0065177 .

In Block 6, $\mathrm{Y}_{1}=-0.2854+0.10827(\mathrm{DD})+0.6249(\mathrm{ED})$ $+0.10002(\mathrm{LD})-0.002909(\mathrm{LS})-0.007465(\mathrm{LST})+$ $0.00006857(\mathrm{R})$. This means that the value -0.2854 is the base constant; that is, the value of $\mathrm{K}$ - factor before the effect of change in the predictor variables is noticed. The equation means that every unit increase in DD, ED, LD and R will increase K - factor by $0.10827,0.6249$, 0.10002 and 0.00006857 respectively, while increase in LS and LST will decrease K - factor by 0.002909 and 0.007465 respectively.

The table above shows that the variables have moderate correlation among each other except for few, and is explained thus:

\begin{tabular}{|c|c|c|c|c|c|c|}
\hline \multirow{2}{*}{$\begin{array}{l}\text { Block } \\
1\end{array}$} & \multirow[b]{2}{*}{ Predictor } & \multicolumn{3}{|c|}{ Coefficient(s) for each Block } & \multirow[b]{2}{*}{$\mathbf{P}$} & \multirow[b]{2}{*}{ VIF } \\
\hline & & $\operatorname{Coef}(\beta)$ & SE Coef & $\mathbf{T}$ & & \\
\hline \multirow{6}{*}{2} & Constant & 0.06541 & 0.03985 & 1.64 & 0.145 & \multirow{4}{*}{$\begin{array}{c}1.000 \\
\text { VIF }\end{array}$} \\
\hline & NDVI & 0.4628 & 0.1870 & 2.47 & 0.043 & \\
\hline & Predictor & Coef & SE Coef & $\mathrm{T}$ & $\mathrm{P}$ & \\
\hline & Constant & -1.0364 & 0.2759 & -3.76 & 0.009 & \\
\hline & LD & 0.07789 & 0.02291 & 3.40 & 0.015 & 1.249 \\
\hline & $\mathrm{R}$ & 0.00013733 & 0.00003184 & 4.31 & 0.005 & 1.249 \\
\hline \multirow[t]{5}{*}{3} & Predictor & Coef & SE Coef & $\mathrm{T}$ & $\mathrm{P}$ & VIF \\
\hline & Constant & 0.00753 & 0.02502 & 0.30 & 0.776 & \\
\hline & ED & 0.5974 & 0.2118 & 2.82 & 0.037 & 3.360 \\
\hline & LD & 0.12172 & 0.02862 & 4.25 & 0.008 & 3.275 \\
\hline & NDVI & 0.5032 & 0.1046 & 4.81 & 0.005 & 1.094 \\
\hline \multirow[t]{6}{*}{4} & Predictor & Coef & SE Coef & $\mathrm{T}$ & $\mathrm{P}$ & VIF \\
\hline & Constant & -0.4672 & 0.2296 & -2.03 & 0.112 & \\
\hline & ED & 0.4233 & 0.1845 & 2.29 & 0.083 & 4.237 \\
\hline & LD & 0.11499 & 0.02244 & 5.12 & 0.007 & 3.345 \\
\hline & NDVI & 0.3477 & 0.1105 & 3.15 & 0.035 & 2.027 \\
\hline & $\mathrm{R}$ & 0.00005993 & 0.00002888 & 2.07 & 0.107 & 2.870 \\
\hline \multirow[t]{7}{*}{5} & Predictor & Coef & SE Coef & $\mathrm{T}$ & $\mathrm{P}$ & VIF \\
\hline & Constant & -0.3397 & 0.1052 & -3.23 & 0.048 & \\
\hline & DD & 0.11055 & 0.02096 & 5.27 & 0.013 & 2.452 \\
\hline & ED & 0.6357 & 0.1008 & 6.31 & 0.008 & 6.638 \\
\hline & LD & 0.102061 & 0.009926 & 10.28 & 0.002 & 3.439 \\
\hline & LST & -0.0065177 & 0.0009110 & -7.15 & 0.006 & 1.291 \\
\hline & $\mathrm{R}$ & 0.00007163 & 0.00001103 & 6.49 & 0.007 & 2.199 \\
\hline \multirow[t]{8}{*}{6} & Predictor & Coef & SE Coef & $\mathrm{T}$ & $\mathrm{P}$ & VIF \\
\hline & Constant & -0.2854 & 0.1384 & -2.06 & 0.175 & \\
\hline & DD & 0.10827 & 0.02318 & 4.67 & 0.043 & 2.500 \\
\hline & ED & 0.6249 & 0.1114 & 5.61 & 0.030 & 6.765 \\
\hline & LD & 0.10002 & 0.01125 & 8.89 & 0.012 & 3.682 \\
\hline & LS & -0.002909 & 0.004109 & -0.71 & 0.552 & 2.926 \\
\hline & LST & -0.007465 & 0.001669 & -4.47 & 0.047 & 3.614 \\
\hline & $\mathrm{R}$ & 0.00006857 & 0.00001283 & 5.34 & 0.033 & 2.481 \\
\hline
\end{tabular}

$\mathrm{DD}$ as a variable has a weak positive correlation with $\mathrm{K}$ factor (0.245) and is not significant at 0.525. This means that DD as a variable alone cannot make any meaningful contribution that will cause any change in $\mathrm{K}$ - factor. ED as a variable has a weak positive correlation with $\mathrm{K}$ - factor (0.034) and is not significant at 0.931. This means that ED as a variable alone even though positive cannot make any meaningful contribution that will cause any change in $\mathrm{K}$ - factor. However, with DD, there is a strong negative correlation (-0.720) and is significant also at 
0.029 which is less than 0.05 level of significance. LD as a variable has a weak positive correlation with $\mathrm{K}$ - factor (0.315) and is not significant at 0.409.

This means that LD as a variable alone cannot make any meaningful contribution that will cause changes in $\mathrm{K}$ - factor. Correlating LD with DD shows a positive relationship (0.570) and is not significant at 0.109 , which is greater than 0.05 level of significance. On the other hand, LD has a strong negative relationship with ED (-0.833) and is significant at 0.005. LS as a variable has a weak positive relationship with $\mathrm{K}$ - factor (0.260) and is not significant at 0.485; compared with DD, it has a weak negative relationship (-0.105), which is not significant at 0.787 ; with ED, it has a very weak positive relationship (0.006) and is not significant at 0.988 and finally with LD, it has a very weak negative relationship $(-0.008)$ and is not significant at 0.984 .

Table 4. Correlation Matrix of the Variables

\begin{tabular}{|c|c|c|c|c|c|c|c|c|}
\hline & \multicolumn{7}{|c|}{ Correlations: K_Factor, DD, ED, LD, LS, LST, NDVI, R, SMI } & \multirow[b]{2}{*}{$\mathbf{R}$} \\
\hline & K-Factor & DD & ED & LD & $\mathbf{L S}$ & LST & NDVI & \\
\hline DD & $\begin{array}{l}0.245 \\
0.525\end{array}$ & & & & & & & \\
\hline ED & $\begin{array}{l}0.034 \\
0.931\end{array}$ & $\begin{array}{c}-0.720 \\
0.029\end{array}$ & & & & & & \\
\hline LD & $\begin{array}{l}0.315 \\
0.409\end{array}$ & $\begin{array}{l}0.570 \\
0.109\end{array}$ & $\begin{array}{r}-0.833 \\
0.005\end{array}$ & & & & & \\
\hline LS & $\begin{array}{c}0.26 \\
0.485\end{array}$ & $\begin{array}{c}-0.105 \\
0.787\end{array}$ & $\begin{array}{l}0.006 \\
0.988\end{array}$ & $\begin{array}{c}-0.008 \\
0.984\end{array}$ & & & & \\
\hline LST & $\begin{array}{c}-0.680 \\
0.044\end{array}$ & $\begin{array}{l}0.037 \\
0.924\end{array}$ & $\begin{array}{c}-0.072 \\
0.854\end{array}$ & $\begin{array}{c}-0.047 \\
0.904\end{array}$ & $\begin{array}{c}-0.747 \\
0.021\end{array}$ & & & \\
\hline NDVI & $\begin{array}{l}0.683 \\
0.043\end{array}$ & $\begin{array}{l}0.271 \\
0.480 \\
\end{array}$ & $\begin{array}{l}0.293 \\
0.444 \\
\end{array}$ & $\begin{array}{c}-0.249 \\
0.518 \\
\end{array}$ & $\begin{array}{l}0.383 \\
0.309\end{array}$ & $\begin{array}{c}-0.600 \\
0.087\end{array}$ & & \\
\hline $\mathrm{R}$ & $\begin{array}{l}0.598 \\
0.089\end{array}$ & $\begin{array}{c}-0.229 \\
0.554\end{array}$ & $\begin{array}{l}0.590 \\
0.095\end{array}$ & $\begin{array}{c}-0.447 \\
0.228 \\
\end{array}$ & $\begin{array}{l}0.071 \\
0.857\end{array}$ & $\begin{array}{c}-0.388 \\
0.303 \\
\end{array}$ & $\begin{array}{l}0.693 \\
0.038 \\
\end{array}$ & \\
\hline SMI & $\begin{array}{l}0.607 \\
0.083\end{array}$ & $\begin{array}{l}0.061 \\
0.875\end{array}$ & $\begin{array}{l}0.355 \\
0.349\end{array}$ & $\begin{array}{c}-0.308 \\
0.419\end{array}$ & $\begin{array}{l}0.465 \\
0.208\end{array}$ & $\begin{array}{c}-0.560 \\
0.117\end{array}$ & $\begin{array}{l}0.904 \\
0.001\end{array}$ & $\begin{array}{l}0.806 \\
0.009\end{array}$ \\
\hline
\end{tabular}

Source: SPSS Output, (2020)

LST as a variable has a strong negative relationship with $\mathrm{K}$ - factor (-0.680) and is significant at 0.044; compared with $\mathrm{DD}$, it has a weak positive relationship (0.037) and is not significant at 0.924 ; with $\mathrm{Ed}$, it has a very weak negative relationship (-0.072) and is not significant at 0.854 ; with $\mathrm{LD}$, it has a very weak negative relationship $(-0.047)$ and is not significant at 0.904; and finally with LS, it has a strong negative relationship (0.747) and is significant at 0.021 .

NDVI as a variable alone has a strong positive relationship with K - factor (0.683) and is significant at 0.043; compared with DD, it has a weak positive relationship 0.271 ) and is not significant at 0.480; also compared with ED, it has a weak positive relationship (0.293) and is not significant at 0.444 ; with $\mathrm{LD}$, it has a weak negative relationship (-0.249) and is not significant at 0.518; also with LS, it has a positive relationship (0.383) and is not significant at 0.309 and finally, when compared with LST, it has a strong negative relationship $(-0.600)$ and is not significant at 0.087 . $\mathrm{R}$ as a variable alone has a positive relationship with $\mathrm{K}$ - factor (0.598) and is not significant at 0.089; compared with DD, it has a negative relationship (-0.229) and is not significant at 0.554; also compared with ED, has a positive relationship (0.590) and is not significant at 0.095 ; with $\mathrm{LD}$, it has a negative relationship (-0.447) and is not significant at 0.228 ; also with LS, it has a very weak negative relationship (-0.071) and is not significant at 0.857 and when compared with LST, it has a negative relationship $(-0.388)$ and is not significant at 0.303 ; and finally when compared with NDVI, it has a strong positive relationship (0.693) and is significant at 0.038 .

SMI as a variable alone has a positive relationship with $\mathrm{K}$ - factor (0.607) and is not significant at 0.083; compared with DD, it has a very weak positive relationship (0.061) and is not significant at 0.875; also compared with ED, it has a weak positive relationship (0.355) and is not significant at 0.349 ; with $\mathrm{LD}$, it has a weak negative relationship (-0.308) and is not significant at 0.419 ; also with LS, it has a weak positive relationship (0.465) and is not significant at 0.208 and when compared with LST, it has a negative relationship (-0.560) and is not significant at 0.117 ; when compared with NDVI, it has a very strong positive relationship (0.904) and is significant at 0.001 
and finally when compare with $\mathrm{R}$, it has a strong positive relationship (0.806) and is significant at 0.009.

\section{CONCLUSION}

The research showed that dynamic causative factors Drainage Density, Erosion Density, Lineament Density, Slope Length, Land Surface Temperature, Normalized Difference Vegetation Index, Rainfall and Soil Moisture Index, influence soil susceptibility to, initiate and trigger erosion hazards in Anambra State, Southeastern Nigeria. The approach employed is very important for sustainable land-use management and erosion prevention. Therefore, understanding the appropriate selection or combination of the vital causative factors is required to achieve accurate susceptibility estimate. The major objective is to know the percentage contribution of dynamic causative factors to occurrence of soil erosion in Anambra State. The study was able to pin-point the dynamic CFs such as DD, ED, LD, LS, LST and R, which contributed 99.4\% to Soil Erodibility (K - Factor) that encourages and helps in triggering soil erosion in the study area in addition to other already known and unknown factors of soil erosion called redundant factors in the context of this research.

\section{REFERENCE}

Ayadiuno, R.U. \& Ndulue, D. C. (2021). An Investigation into some Soil Indices as Indicators of High Soil Erodibility in Anambra State Southeastern, Nigeria. IJMA, 10(2), 3451 - 3464. Retrieved from http:// www.modern-journals.com/index.php/ijma/article/ view/1187

Egboka, B.C.E., Orji, A.E., \&t Nwankwoala, H.O. (2019). Gully Erosion and Landslides in Southeastern Nigeria: Causes, Consequences and Control Measures. Glob J Eng Sci. 2(4): GJES.MS.ID.000541. DOI: 10.33552/ GJES.2019.02.000541

Egbueri, J.C, \& Igwe, 0. (2020). The impact of hydrogeomorphological characteristics on gullying processes in erosion-prone geological units in parts of southeast Nigeria. Geol Ecol Landsc. https://doi.org/10 $.1080 / 24749508.2020 .1711637$

Emeh, C., \& Igwe, 0. (2018). Effect of Environmental Pollution on Susceptibility of Sesquioxide-rich Soils to Water Erosion. Geology, Ecology, and Landscape, vol. 2, No. 2, 115-126.

Farauta, B.K., Egbule, C.L., Agwu, A.E., Idrisa, Y.L. \& Onyekuru, N.A. (2012). Farmers' Adaptation Initiatives to the Impact of Climate Change on Agriculture in Northern Nigeria, Journal of Agricultural Extension Vol. 16 (1), June 2012: http://dx.doi.org/10.4314/jae. v16i1.13

Ifejofor, M. (2019). Revealed: Over 1000 Gully Erosion Site Captured in Anambra. https://www.vanguardngr. com/2019/03/revealed-over-1000-gully-erosion-sitescaptured-in-anambra/ March 292019 (Accessed on 19 July 2021)

Igbokwe, J.I., Ezeomedo, I.C. \& Ejikeme, J.C. (2013). Identification of urban sprawl using GIS technique: A case study of Onitsha and its environs in Southeast, Nigeria. International Journal of Remote Sensing \& Geoscience, 2, 41-49, 2013.

Igwe, 0. \&t Egbueri, J.C. (2018). The Characteristics and the Erodibility Potentials of Soils from Different Geologic Formations in Anambra State, Southeastern Nigeria, Journal of the Geological Society of India. 92, 471-478 (2018). https://doi.org/10.1007/s12594-0181044-1

Jafar-zadeh, A., Unus, G., Shahin, 0. \& Ahmad, A. (2014). The Effect of Clay Minerals on Soils Interrill Erodibility Factor and Management in Dast-e Tabriz. Asia Pacific Journal of Sustainable Agriculture Food and Energy (APJSAFE) Vol. 2 (2): 23-31.

Ndukwe, C., Okeke, F.I., Nwosu, K., Ibe, C., Ndukwu, R. \& Ugwuoti, A. (2013). The Role of Surveying and Mapping in Erosion Management and Control: Case of Omagba Erosion Site, Onitsha Anambra State, Nigeria. Journal of Environment and Earth Science, Vol. 3, No. 11.

Ndulue, D.C., Ayadiuno, R.U., Mozie, A.T. \&t Ndichie, C.C. (2021). A Comparative Analysis of Soil Erosion Models for Tropical Humid of Southeastern Nigeria and Comparable Environments. PSYCHOLOGY AND EDUCATION (2021) 58(1): 5821-5835

Nwajide, C.S (2013). Geology of Nigeria's sedimentary basins. CSS Bookshops Limited, Abuja, p 565

Nwunonwo, U.C. (2013). GIS-Based Digital Map for Gully Erosion Management in Anambra Southeastern Nigeria. International Journal of Current Research, 5(9), pp 2649-2653.

Shakirudeen, O., Abiodun, A., Igwetu, N. and Olubunmi, A. (2018). Proceedings of IAHS, 376, 87-95, 2018.

Shi, Z.H., Ai, L., Li, X., Huang, X.D., Wu, G.L., and Liao, W. (2013). Partial Least-Squares Regression for Linking Land-cover Patterns to Soil Erosion and Sediment Yield in Watersheds. Journal of Hydrology, 498, 165-176. United States Geological Survey (USGS). https:// earthexplorer.usgs.gov. (Accessed on 12 June, 2021). Wischmeier, W.H. (1960), Cropping management factor evaluations for a universal soil loss equation. Soil Sci. Soc. Am. Proc. Vol 23, pp 322326. 